\title{
MÍDIA E EDUCAÇÃO: EDUCAÇÃO EM REDE
}

\author{
Lucyene Lopes da Silva Todesco Nunes ${ }^{1}$ \\ Neusa de Oliveira Carneiro ${ }^{2}$ \\ Márcio Vieira de Souza ${ }^{3}$ \\ José Leomar Todesco ${ }^{4}$ \\ Maria José Baldessar ${ }^{5}$
}

\section{INTRODUÇÃO}

O meio em que vivemos contribui para o nosso entendimento da vida e das coisas. Em instituições escolares existem pessoas com diferentes saberes e formas de se relacionar que devem ser repassados aos demais. As instituições de ensino e pesquisa colaboram para a geração do conhecimento no novo paradigma tecnológico, estruturado em torno de novas tecnologias de informação e comunicação (CASTELLS, 2007). A comunicação possui um papel importante de relação entre as pessoas e o contexto, tornamo-nos dependentes da comunicação para o desenvolvimento e compartilhamento do conhecimento. $O$ objetivo deste artigo é reforçar o construto de educação em rede através da Mídia e Educação como sistema integrador de agentes humanos e tecnológicos "inteligentes".

Seguindo por outro lado, enquanto temos na sociedade em rede 0 aumento do compartilhamento do conhecimento, permanece o desafio da comunicação de visões de mundo, de estruturas de pensamento e da quebra das tradições e interesses de poder sobre o domínio de conhecimento (GALDO, 2010).

Antes de começar com o tema educação em rede neste artigo iniciaremos com uma temática anterior: Mídia e Educação. Desta forma com as letras iniciais maiúsculas com a intenção de ressaltar o construto.

Mídia e Educação é mais forte que mídia sozinha e mais forte do que educação, sozinha. Palavras que sozinhas já se tornam fortes e complexas.

\footnotetext{
1 Universidade Federal de Santa Catarina (UFSC), Doutoranda do Programa de PósGraduação em Engenharia e Gestão do Conhecimento (PPGEGC), lucyene@ifc-sombrio.edu.br;

2 UFSC, Doutoranda do PPGEGC,

3 UFSC, Professor do PPGEGC e do Programa de Pós-Gradução em Tecnologia da Informação e Comunicação (PPGTIC), marcio

4 UFSC, Professora do PPGEGC e do Programa de Pós-graduação em Educação,

$5 \quad$ UFSC, Professor do PPGEGC
} 
Juntas montam todo um sistema para contribuir com a disseminação do conhecimento na educação. Belloni (2005, p. 12) afirma que Mídia-Educação corresponde à educação para as mídias. É um novo campo de saber, cujos "objetivos visam à formação do usuário ativo, crítico e criativo de todas as tecnologias de comunicação e informação (TIC)".

As TIC favorecem a difusão do conhecimento e estão disseminadas na sociedade, porém, na educação sua utilização ainda é incipiente. Para que as TICs possam provocar mudanças na educação, "...precisam ser compreendidas e incorporadas pedagogicamente" (KENSKI, 2007, p. 46). As TICs estão fortemente relacionadas a capacidade: à capacidade de aprendizagem da sociedade; à construção de modelos de representação organizacional; à estruturação de uma sociedade em rede; às diferentes formas de relacionamento; e à mudança na perspectiva do pensamento complexo.(XAVIER, 2010, p. 354)

Contudo para Teixeira, Vezozzo e Matos (2015) a desatenção proporcionada pelas mídias traz pontos negativos. Os autores afirmam que são muitas informações recebidas, diálogos com amigos, vídeos interativos e cômicos transmitidos pelos meios de comunicações, durante o dia.

A utilização de aplicativo em Smartphones configura a geração atual como estudantes com pouco interesse nos conteúdos transmitidos pelos professores e os direcionam, no tempo presente em sala, para busca de conteúdos alheios a disciplina, que são mais cômodos e interessantes na visão individual do discente (TEIXEIRA, VEZOZZO e MATOS, 2015, p. 305).

Possuímos um desafio na Mídia e Educação, o uso adequado dos recursos para fins educacionais.

\section{METODOLOGIA}

Para a elaboração desse artigo realizou-se uma pesquisa teórica de cunho descritivo através de uma revisão sistemática. A pesquisa caracteriza-se como bibliográfica.

Prevaleceu-se a abordagem qualitativa. O conceito de conhecimento aqui estalecido será o de Maturana e Varela (1995) que contribuem ao falar 
que conhecimento é toda vez que verifica-se uma conduta efetiva (ou adequada) num contexto assinalado, ou seja, num domínio que se defini com uma pergunta que formulou-se como observadores. Perassi (2010) propõe a ampliação do conceito de conhecimento com a criação e o desenvolvimento dos agentes tecnológicos "inteligentes” capazes de organizar informações em novas informações ou conhecimentos. Idem (2010) propõe a "mídia do conhecimento" como sistema integrador de agentes humanos e tecnológicos "inteligentes". A pesquisa, aqui apresentada, é de caráter exploratória, e teve como objetivo conceder maior conhecimento com o problema, com vistas a torná-lo mais explícito. Segundo Gil (2002) essas pesquisas envolvem levantamento bibliográfico como também análise de exemplos que fortaleçam a compreensão. Para identificar alguns construtos para serem utilizados de guia para esse trabalho foi realizada uma busca sistemática de literatura em bancos de artigos científicos.

O quadro 01 demonstra o resultado da busca nos Periódicos da Capes. Os termos utilizados foram: "Educação em Rede" e "Tecnologias Digitais". No primeiro momento a busca foi realizada sem nenhuma restrição, porém com os dois termos juntos, resultou em 129 trabalhos. No segundo momento, solicitou-se a busca com os dois termos, somente no título, com resultado, zero. E a terceira busca foi a localização de um dos termos, no título ou nas palavras-chave, resultando em nove trabalhos: uma tese, duas dissertações, três artigos e uma resenha.

Quadro 1 - Resultado da busca nos periódicos da Capes

\begin{tabular}{|c|c|c|}
\hline Nome (tipo de material) & Autores & Ano \\
\hline $\begin{array}{c}\text { As tecnologias midiáticas e digitais de } \\
\text { informação e comunicação (TMDICs) e a } \\
\text { educação contemporânea (artigo) }\end{array}$ & $\begin{array}{c}\text { Leandro Petarnella eMaria } \\
\text { Lucia de Amorim Soares }\end{array}$ & 2010 \\
\hline $\begin{array}{c}\text { Psicologia do desenvolvimento, educação a } \\
\text { distância e as tecnologias digitais da } \\
\text { informação e da comunicação (artigo) }\end{array}$ & Fabio Scorsolinicomin & 2014 \\
\hline $\begin{array}{c}\text { Tecnogias digitais de informação e } \\
\text { comunicação (TDIC) em educação escolar: } \\
\text { um diagnóstico a partir da formação inicial } \\
\text { de professores de matemática (artigo) }\end{array}$ & Raquel Gomes de Oliveira & 2012 \\
\hline
\end{tabular}




\begin{tabular}{|c|c|c|}
\hline $\begin{array}{l}\text { Formação para uso das tecnologias digitais } \\
\text { de informação e comunicação nas } \\
\text { licenciaturas das universidades estaduais } \\
\text { paulistas (dissertação) }\end{array}$ & Rosemara Perpetua Lopes & 2011 \\
\hline Docência virtual: uma visão crítica (resenha) & Ketiuce F. Silva & 2014 \\
\hline $\begin{array}{c}\text { Objetos de aprendizagem: ferramentas } \\
\text { tecnológicas naeducação executiva } \\
\text { (dissertação) }\end{array}$ & Douglas Gregorio Miguel & 2012 \\
\hline $\begin{array}{l}\text { Apropriação das tecnologias de informação } \\
\text { e comunicação pelos gestores educacionais } \\
\text { (tese) }\end{array}$ & $\begin{array}{c}\text { Marilene Andrade Ferreira } \\
\text { Borges }\end{array}$ & 2009 \\
\hline $\begin{array}{l}\text { Histórias digitais: narrativas no século XXI. } \\
\text { O software Movie Maker como recurso } \\
\text { procedimental para construção de } \\
\text { narrações (dissertação) }\end{array}$ & Gracinda Souza de Carvalho & 2008 \\
\hline
\end{tabular}

Fonte: os autores, 2016.

\section{RESULTADOS E DISCUSSÃO}

Comunicação é uma forma inteligente de agir através de agentes e tecnologias. Importante as instituições de ensino, junto a seus sujeitos, preocuparem-se com o meio, com o como e com o que está envolvido no ensino e na aprendizagem. Gomez (2009) considera que as alterações origina-se do uso da internet nos diversos espaços sociais este espaço está questionando o ensino e aprendizagem e a geração de uma nova sociabilidade resulta na densidade humana na esfera virtual.

É uma demanda para a escola contemporânea de ensino médio: a de abandonar os saudosismos do passado e de uma sociedade e juventude que não existem mais, para aceitar novas produções bem como de uma nova conjuntura social na qual a tecnologia e suas novas mídias inauguram novos modos de obter informações, comunicar-se e se relacionar com o conhecimento (OLIVEIRA, TOMAZETTI, 2010). Tablets, wifi, ebooks, gadgets, notes e nets. Facebook, blogs, tubes, wikis, tweets. Acesso imediato, interatividade, informação total. As tecnologias de informação e comunicação estão mudando dramaticamente as formas de trabalho, de socialização, de comunicação e, como não poderia deixar de ser, da aprendizagem (SABBATINI, 2011).

Criando uma ideia de compartilhamento como Merton define poderíamos ter na educação um modelo novo de proposição de ideias. A ascensão da obra 
magistral de Merton à posição de modelo teórico e metodológico para a sociologia da ciência sela, definitivamente, o pacto de silêncio ao qual se submeteram a história e a sociologia da ciência. As investidas sociológicas estavam restritas a limites estreitos, bem delimitados e bem policiados. (ÁVILA, 2012 in FIGUEREDO, 2012). Educação em rede é um conjunto de ideias e sujeitos para contribuir com a disseminação do conhecimento. É um modo de provocação a fim de que se reflita. Ideia esta quer seja de modo virtual ou presencial.

A rede é um elemento de ligamento e envolvimento, mas também de devoração e pulverização num mundo globalizado (GOMEZ, 2000). O presencial se virtualiza e a distância se presencializa. Os encontros em um mesmo espaço físico se combinam com os encontros virtuais, a distância, através da Internet (MORAN, 2003).

O mundo vive em rede. Vamos utilizar o que há de melhor para educação em rede e neste sentido é preciso verificar que tipo de rede. É interessante notar que as redes compostas por fractais, base conceitual da educação em rede, são também redes sociais, ou seja, formas de organização humana e de articulação entre grupos e instituições. (SOUZA, SIMON, 2014).

A rede prescinde de pessoas, várias delas. A construção se faz com o conhecimento de todos, podemos classificar como inteligência coletiva. Lévy (1998) denomina de uma inteligência coletiva, que se constrói no ambiente da/em Rede, esta inteligência, para ele, não prescinde da inteligência pessoal, do esforço individual e do tempo necessário para aprender, pesquisar, avaliar e integrar-se a diversas comunidades, sejam elas virtuais ou não.

As instituições de ensino e pesquisa colaboram para a geração do conhecimento no novo paradigma tecnológico, estruturado em torno de novas tecnologias de informação e comunicação (CASTELLS, 2007). Gomez (2009) considera que as alterações origina-se do uso da internet nos diversos espaços sociais este espaço está questionando o ensino e aprendizagem e a geração de uma nova sociabilidade resulta na densidade humana na esfera virtual.

É inegável o potencial da Internet para comunicação e constitui um campo propício para abrigar a diversidade cultural, a educação, a arena política, o panorama econômico, contudo persiste a necessidade de determinar processos de inclusão digital para que as pessoas com menor poder aquisitivo e menos escolaridade tenham acesso às TICs (CURY \& CAPOBIANCO, 2011). 
Para Castells (2007), a intensidade e a frequência da interação entre atores sociais são maiores se esses atores forem nós de uma rede do que se não pertencerem a ela. A capacidade da rede, de conectar e desconectar nós, sempre achando novos caminhos para que a comunicação não seja interrompida, deve ser utilizada para aproximação entre as pessoas e as organizações (RAMOS JÚNIOR, 2010, p. 299)

\section{CONSIDERAÇÕES FINAIS}

O mundo como uma rede de conhecimento e sujeitos busca diminuir distâncias através das tecnologias da comunicação. Estamos na era do compartilhamento de ideias, coisas e consequentemente conhecimento, Freire (2014) afirma que não é no silêncio que os homens se fazem, mas na palavra, no trabalho, na ação-reflexão. Conhecimento como commons nas palavras de Ostrom e seus oito princípios adaptados em uma rede de educação. Com delimitações, regras e fluxos para uma comunidade, uma rede. Segundo Fialho et al. (2006, p. 2) citado por Obregon (2015) "Construir conhecimento nas organizações é construir um poder de interagir de forma diferente com o meio; é também construir uma aprendizagem que tem de ser amplamente partilhada para produzir efeitos positivos". Mídia como possibilidade real de compartilhamento do conhecimento. "A organização social em comunidades ou redes vivas permite uma maior produção e compartilhamento de conhecimento, oque promove mudanças na cultura, na ciência, na sociedade e nas insituições" (XAVIER, 2010, p. 353). "A escola passa a se tornar um espaço de construção do conhecimento, onde as diferenças, as experiências, as informações oriundas de outras redes educativas que cada praticante forma e se forma são levadas em conta, contribuindo todos para o aperfeiçoamento contínuo do saber" (ROSSINI \& SANTOS, 2015).

$\mathrm{Na}$ revisão sistemática constatou-se um baixo número de trabalhos com os termos "Educação em Rede" e "Tecnologias Digitais", considerando o contexto de crescimento da Educação em Rede. Percebemos que os dois temas aqui tratados não se esgotam aqui, e sim a pesquisa bibliográfica nos remete a identificação de um vasto campo de estudo que podem contribuir com o desenvolvimento e amplificação dos construtos. 


\section{REFERÊNCIAS}

ÁVILA, G. C. in FIGUEIREDO, B. G. (Org.) e Outros. Biografia e história das ciências. Debates com a História da historiografia. 1. ed., v. 1, Ouro Preto: Editora da Universidade Federal de Ouro Preto, 2012.

BELLONI, Maria Luiza. O que é mídia educação. Campinas, SP. 2 d. Autores Associados, 2005.

BORGES, M. A. F. Apropriação das tecnologias de informação e comunicação pelos gestores educacionais, 2009. $320 \mathrm{f}$. Tese (Doutorado em Educação) Pontifícia Universidade Católica de São Paulo -PUC, São Paulo, 2009.

CARVALHO, G. S. Histórias digitais: narrativas no século XXI. O software Movie Maker como recurso procedimental para construção de narrações, 2008. $196 \mathrm{f}$. Dissertação (Mestrado em Educação) - Universidade de São Paulo, São Paulo, 2008.

CASTELLS, M. A sociedade em rede. Vol. 1. 10 ed. Tradução de Roneide Venâncio Majer. São Paulo: Paz e Terra, 2007.

CURY, L.; CAPOBIANCO, L. Princípios da história das tecnologias da informação e comunicação: grandes invenções. VIII Encontro Nacional de História da Mídia UNICENTRO, Guarapuava - PR- 28 a 30 de abril de 2011.

FIALHO, F.A.P.; MACEDO, M.; SANTOS, N. dos; MITIDIERI, T. da C. Gestão do conhecimento e aprendizagem: as estratégias competitivas da sociedade pós-industrial. Florianópolis: Visual Books, 2006.

FREIRE, P. Pedagogia do oprimido. Rio de Janeiro: Paz e Terra. 56. ed. rev. e atual. São Paulo: Paz e Terra, 2014.

GALDO, A. A evolução do conhecimento científico na perspectiva da complexidade. In: $O$ sujeito do conhecimento na sociedade em rede, ROVER, A. J.; CARVALHO, M. A. (org.), Florianópolis: Fundação José Arthur Boiteux, 2010.

GIL, A. C. Como elaborar projetos de pesquisa. 4. ed. São Paulo: Atlas, 2002.

GOMEZ, M. V. Redes e Cadeias na educação. In: Revista Brasileira de

Biblioteconomia e Documentação. São Paulo, v. 1, n.2, p. 37-47, 2000.

GOMEZ, M.V. Emmanuel Levinas and Paulo Freire: The Ethics of Responsibility for the Face-to-Face Interaction in the Virtual World.

International Journal of Instruction , v. 57, p. 27, 2009.

KENSKI, V. M. Educação e tecnologias: o novo ritmo da informação. Campinas: Papirus, 2007.

LÉVY, P. A inteligência coletiva: por uma antropologia do ciberespaço. Tradução Luiz Paulo Rouanet. São Paulo: Edições. Loyola,1998. 
LOPES, R. P. Formação para uso das tecnologias digitais de informação e comunicação nas licenciaturas das universidades estaduais paulistas. 2011. 224 f. Dissertação (Mestrado em Educação) - Universidade Estadual Paulista Júlio de Mesquita Filho, UNESP, Presidente Prudente, 2011.

MATURANA R., H.; VARELA G. F. A Árvore do conhecimento: as bases biológicas do entendimento humano. Campinas, SP. Editorial Psy II, 1995.

MIGUEL, D. G. Objetos de aprendizagem: ferramentas tecnológicas na educação executiva. 2012. 146 f. Dissertação (Mestrado em Ciências da Comunicação) - Universidade de São Paulo, São Paulo, 2012.

MORAN, J. M. Educação inovadora presencial e a distância, 2003.

Disponível em:http://www.eca.usp.r/prof/moran/inov_1.htm Acesso em: mai 2016.

OBREGON, R. F. A.; VANZIN, T. ; ULBRICHT, V. R. AVA inclusivo: recomendações para design instrucional na perspectiva da alteridade. 1. ed., v. 1, São Paulo: Pimenta Cultural, 2015.

OLIVEIRA, A. M.; TOMAZETTI, E. M. Novos sujeitos no ensino médio? Reflexões acerca da subjetivação juvenil no cenário escolar contemporâneo. Acta Scientiarum. Education (Online), v. 32, p. 127-134, 2010.

OLIVEIRA, R. G. Tecnologias digitais de informação e comunicação (TDIC) em educação escolar: um diagnóstico a partir da formação inicial de professores de matemática, Nucleus (Ituverava. Impresso), v. 9, p. 351-361, 2012.

PERASSI. R. L. S. Conhecimento, mídia e semiótica na área de mídia do conhecimento. EGC/UFSC. Florianópolis, SC: EGC/UFSC. 2010.

PETARNELLA, L.; DE AMORIM SOARES, M. L. As tecnologias midiáticas e digitais de informação e comunicação (TMDICs) e a educação contemporânea. Eccos Revista Científica(impresso), v. 12, p. 181-194, 2010.

RAMOS JÙNIOR, H. S.; RUSCHEL, A. J.; ALBUQUERQE, A. S.; TADEU, A. As tecnologias da informação e comunicação na sociedade em rede. ROVER, A. J.; CARVALHO, M. A. (org.), O sujeito do conhecimento na sociedade em rede.

ROSSINI, T. S. S.; SANTOS, E. Recursos educacionais abertos: desafios para autoria e formação de professores na Cibercultura. In: TORRES, P. L. (Org.) Redes e Mídias Sociais. Curitiba: Ed. Appris, 2015.

SABBATINI, M. Sob o signo da convergência: reflexões sobre o papel das mídias digitais interativas na educação. Artigo apresentado na 34르 reunião da ANPED - associação nacional de pesquisa e pós-graduação em educação, natal, rio grande do norte, outubro de 2011. 
SCORSOLINI-COMIN, F. Psicologia do desenvolvimento, educação a distância e as tecnologias digitais da informação e da comunicação. Psico(PUCRS.

Impresso), v. 44(3), p. 352-361, 2013.

SILVA, K. F. Docência virtual: uma visão crítica. Revista Eletrônica de Educação, v. 8 (2), 406 - 411, 2014.

SOUZA, M. V.; SIMON, R. M. Redes sociais e MOOCs: análise de mídias para uma educação em rede. In: ESUD - XI Congresso Brasileiro de Ensino Superior a Distância, p. 313-327. NUTE-UFSC. Florianópolis - SC, 2014.

TEIXEIRA, A. M.; VEZOZZO, C.; MATOS, E. L. M. A interação entre os saberes docentes, tecnologias e as redes na visão dos alunos do ensino superior. In: TORRES, P. L. (Org.) Redes e Mídias Sociais. Curitiba: Ed. Appris, 2015.

XAVIER, L. S.Organizações caórdicas: uma evolução das redes sociais na perspectiva científica da teoria da complexidade. In: ROVER, A. J.; CARVALHO, M. A. (org.), O sujeito do conhecimento na sociedade em rede. Florianópolis: Fundação José Arthur Boiteux, 2010. 